\title{
Georges Duby e o outro lado do Feudalismo
}

Hilário Franco $\mathrm{Ir}$.

Doutor em História -- USP

Não se trata aqui, intencionalmente, de fazer um balanço da produção historiográfica de Georges Duby, toda ela voltada para a Idade Média Central, para os séculos X-XII, portanto para a época feudal. Seria na verdade un bom momento para tanto - este ano completam-se 30 anos do surgimento de sua primeira obra, sua tese sobre o Mâcon feudal: La société aux XI et XII siècles dans la région mâconnaise. Paris, Armand Colin, 1953 (nova edição: Paris ,Jean Touzot, 1971) - porém esta tarefa escapa de momento às nossas possibilidades. Assim, pretendemos apenas tecer algumas considerações sobre as duas obras do grande medievalista: Les trois ordres ou l'imaginaire du féodalisme. Paris, Gallimard, 1978 e Le chevalier, la femme et le prête. Paris, Hachette, 1981.

Nestas duas obras, Duby avança acentuadamente na direção que já se esboçava desde Guerriers et paysans (1973) e Le temps de cathédrales (1976), ou seja, de extravasar os quadros limitativos de um campo de estudo restrito que os historiadores se impóem a si próprios. Se, ao contrário do que os subtítulos indicam, a obra de 1973 já não era de história econômica no sentido clássico e a de 1976 não apenas sócioartística, nas duas que ora examinamos a pretensão globalizante se corporifica mais claramente. Sua proposta metodológica é de estudar uma 
totalidade histórica, e na longa duração, não apenas por razões práticas de pesquisa e de maior rigor científico, mas sobretudo por coerência ao papel que vê em seu métier, pois "o conhecimento da História é, no fundo, indispensável à compreensão do presente e ser historiador só tem sentido se ajudarmos nossos contemporâneos a dominar melhor os problemas que se lhes apresentam" (1).

Por esta razão, Les trois ordres começa por citar um documento do século XVII, verifica a presença da mesma idéia no XX e fecha com uma referência às vésperas da Revolução Francesa. Percebendo esses ecos do modelo de trifuncionalidade social formulado nos princípios do século $\mathrm{XI}$, compreendemos que "esta representação mental resistiu a todas as pressões da História. E uma estrutura" (2). Justificado assim o interesse de seu objeto de estudo, Duby passa a perseguir essa figura, esse fantasma, aprisionado segundo sua bela imagem, "nas muralhas do imaginário" (3). Seu caminho em busca dessa imagem se faz através de cinco etapas: revelação, gênese, circunstâncias, eclipse, ressurgimento.

A revelação do modelo ideológico trifuncional é acompanhado nos seus primeiros enunciados através da análise dos textos e contextos de seus formuladores iniciais, Adalberon de Laon e Gérard de Cambrai. Mas como esses bispos tinham se utilizado de um material antigo para a edificação de seu sistema, ao estudar sua gênese Duby faz uma admirável arqueologia de termos e expressões, reconstruindo os textos de Adalberon e Gérard a partir das autoridades de que eles haviam se servido, Padres da Igreja, excertos bíblicos, cronistas e hagiógrafos. Assim, ele nos mostra as peças-chaves de seu quebra-cabeça, da concepção não original mas ordenada de forma nova, a partir de peças velhas, pelos dois bispos: hierarquia, concórdia, ordens, funcionalidade, ternaridade, exemplaridade celeste.

Tal sistema ideológico, como todos, não era reflexo do vivido mas projeto de agir sobre ele (4): "o discurso dirige-se ao rei. Finge defender a monarquia. Mas de fato quer domesticá-la. O rei já não é o árbitro, é o executante, o defensor, para retomar o vocabulário das instituições carolíngias o braço secular, o instrumento de um poder que Deus outorga diretamente aos prelados da Igreja" (5). Também como parte da lógica

(1) - Entrevista a André Burguière do Nouvel Observateur, publicada no Suplemento Cultural de $O$ Estado de São Paulo de 23/1/1983 p. 8.

(2) - Les trois ordres p. 16.

(3) - Ibidem p. 390.

(4) - Duby, G. História social e ideologia das sociedades in Le Goff, $J$. e P. Nora (dir.) História: novos problemas trad. port. Rio, Francisco Alves, 1976, pp. 130-145.

(5) - Les trois ordres, p. 150-151. 
das ideologias, o modelo dos bispos - "porque não se substituiriam ao rei, e uma vez que eram também sagrados, porque não assumiriam abertamente a defesa da ordem terrestre?" (6) - enfrentava sistemas concorrentes que tinham outros projetos para remediar a fragilidade da realeza: o modelo herético, o modelo da Paz de Deus, o modelo monástico cluniacense. Contra o primeiro deles por propor a igualdade social total, contra o segundo por demagogicamente poder libertar a força das reivindicações populares, contra o terceiro por escapar à autoridade episcopal.

Logo, o sistema ideológico de Adalberon e Gérard era uma reação (7). Mas ele se aproxima desses dois últimos concorrentes por estarem todos os três contra o herético, perigoso no seu radicalismo e anti-clericalismo. $\mathrm{Na}$ verdade, o modelo episcopal, o da Paz de Deus e o cluniacense buscaram todos uma nova configuração social, uma ordem que correspondesse às intenções divinas. A divergência estava apenas na "estratégia capaz de defender os interesses dos senhores eclesiásticos" (8). Nesse contexto, entende-se a pretensão clerical de normatizar a sociedade não só na visão global que ela teria de si mesma, mas, para que isso tivesse sucesso, também no seu sistema de reprodução biológica e social. Daí a institucionalização do casamento, "instrumento de controle" (9).

Deparamo-nos assim com a questão central da obra, a produção ideológica por parte de um certo segmento da camada dominante feudal. Porém, no seu título o livro não utiliza a expressão "ideologia", preferindo "imaginário", e, assim nos parece, exprimindo equivocadamente seu conteúdo. Seguindo Jacques Le Goff, acreditamos que "ideologia" (a idéo-logique de Marc Augé) deva ser vista como representação conceitual, isto é, a ideologia é expressão da estrutura da sociedade, instrumento para pensá-la e para impor uma visão de interesses dos produtores ideológicos (10). Por outro lado, o imaginário é constituido pelo conjunto de símbolos criados ficcionalmente ou emergidos do inconsciente coletivo (11).

De qualquer forma, a partir das circunstâncias das primeiras décadas do século XI, Duby examina o sucesso da triuncionalidade, que

(6) - Ibidem, p. 160 .

(7) - Ibidem, pp. 81, 179, 201.

(8) - Ibidem, p. 200.

(9) - Le chevalier, p. 303.

(10) - Le Goff, J., Les trois fonctions au Moyen Age, Annales (ESC) 34, 1979 , p. 1208 .

(11) - Patragean, E. L'histoire de l'imaginaire, in Le Goff, J. (dir.) La nouvelle histoire. Paris, CEPL, 1978 p. 249-269; Jung, C. G. (dir.), $O$ homem e seus símbolos trad. port. Rio, Nova Fronteira, $3^{\mathrm{a}} \mathrm{ed} . \mathrm{s} / \mathrm{d}$. 
ao mesmo tempo exprimia os antagonismos na camada dominante expressão da concorrência aos benefícios produzidos pelo novo sistema de exploração, pela "revolução feudal" - e a dominação conjunta sobre o terceiro elemento. Este, os laboratores, formavam uma massa produtora e sofredora (labor, dolor, sudor) que resgatatava o pecado original pelo suor de seu rosto, pelo trabalho, espécie de penitência. Esquema reacionário, por tanto, por não aceitar que a purificação, objetivo dos reformadores monásticos, se estendesse a toda sociedade. De fato, 0 pecado é fonte de desigualdade e desta provêm as condições do laicato, em que a impureza pode ser redimida pelo sofrimento físico dos trabalhadores e pela dedicação da vida a uma boa causa, a uma guerra santa, do lado dos guerreiros.

Mas o modelo ideológico dos bispos foi abalado em 1031 pelo enfraquecimento da realeza capetíngia que provocou o da instituição episcopal. Isto canalizou para os mosteiros reformados o fervor dos laicos e suas esmolas, no momento em que o progresso agrícola, o feudalismo e Cluny despontavam de forma integrada no processo histórico. O modelo cluniacense na verdade definia duas sociedades terrestres, uma secular, trifuncional, outra monástica, ante-sala da Sociedade Celeste. Assim, Cluny se aproveita da idéia, que aos poucos ganhava força, de um purgatório (12) de onde as almas poderiam ser retiradas pelo serviço dos vivos, isto é, pela liturgia fúnebre cluniacense, pois "a ordem é, antes de tudo, o exército dos mortos" (13). Nesse esquema "feudal", os reis são desnecessários, aos monges negros basta o Rei dos reis; Cluny assume as três funçóes sociais como outrora $\circ$ rei, levando-as para a unidade original, restabelecendo aos poucos o homogêneo, migrando para a Salvação.

Mas os monges voltavam as costas ao mundo, enquanto o clero pretendia adequá-lo ao desejo de Deus. Os bispos reformadores não pretendiam, contudo, rebaixar o monarquismo, mas igualá-lo, impor a todos os clérigos a pureza dos monges. Assim ,da reforma gregoriana emergiu a bipartição castidade-matrimônio, presente mesmo na última fulguração do monarquismo: para Guilbert de Nogent há uma hierarquia de méritos definida pela pureza sexual. Um século depois um clérigo secular, um bispo, Jacques de Vitry, retomava tal classificação social pela atividade sexual, vendo a ordem perfeita apenas na inserção de todo laico numa ordo através da conjugabilidade. Reforçava-se a moral sexual imposta aos laicos como forma de submetê-los e manobrá-los.

(12) - Este ponto foi posteriormente confirmado e ampliado na grande obra de Le Goff, J. La naissance du Purgatoire, Paris, Gallimard, 1981, p. 170-173. (13) - Les trois ordres, p. 247. 
Por outro lado, desde fins do século XI os clérigos buscavam uma vida apostólica que os fizesse prevalecer sobre os monges: "a missão específica do clero era chamar à vida pelo batismo, alimentar pela eucaristia, retificar pela penitência, controlar enfim a renovação da sociedade pelo matrimônio que, no último terço do século XII, passou a fazer parte dos sete sacramentos da Igreja" (14). Ao ter maior contato com o mundo, a visão do clérigo se multifaceta, outras figuras sociais se impõem, como a de virgens, continentes e casados, pois "com efeito, sobre o casamento repousava agora, aos olhos da Igreja, toda a ordem moral" (15). De fato, o casamento ao estabelecer relaçōes de parentesco fundamenta todo o edifício social e assim o estudo de suas formas complementa o da trifuncionalidade (16).

Por volta de 1180 retoma-se o esquema das três ordens, mas alicerçando não uma moral religiosa e sim cívica; o modelo ternário foi dessacralizado. Em suma, surgido em 1025, o esquema trifuncional ficou século e meio na obscuridade: "a interrupção corresponde ao enfraquecimento do Estado monárquico, ao entreato feudal" (17). Mas ressurge diante da institucionalização da cavalaria, do medo social, do rei enfim visto como mantenedor do modelo tripartido, promovedor do equilíbrio social, imagem que se manteria por séculos, deixando então de ser uma figura imaginária para se corporificar numa engrenagem institucional e numa organização concreta da sociedade.

Brilhante. Sem dúvida Les trois ordres nos desperta espontaneamente o adjetivo. Contudo, e esta é uma das grandes virtudes da obra de Duby, chegamos ao fim dela insaciados. Percorrido o longo caminho de 425 páginas através de um raciocínio claro, lúcido, rigoroso e de estilo impecável, lamentamos não ter sido possível adentrar por todas as vias laterais, explorar mais a fundo cada pequeno momento de todas as etapas. Não que o autor tenha se furtado a isso. Pelo contrário, a obra é um conjunto - extremamente bem articulado - de pequenas mas extraordinárias monografias. Suas páginas, por exemplo, sobre Raul Glaber (p. 236-243) ou a cavalaria (p. 352-370) formam conjuntos que fundem harmoniosamente erudição, rigor metodológico e qualidade literária.

Infelizmente, contudo, a extensão do texto impediu que Duby fundamentasse suficientemente certas passagens, correndo o risco de alguns enunciados dogmáticos e algo simplificados. Para ficarmos num

(14) - Ibidem, p. 285.

(15) - Ibidem, p. 310 .

(16) - Le chevalier, p. 23-24.

(17) - Les trois ordres, p. 343. 
único exemplo, ao tratar das transformaçōes estruturais da Igreja em princípios do século XII, liga-as "aos movimentos profundos que tiravam lentamente a civilização ocidental da ruralidade", o que provocava modificações na visão dos homens cultos sobre a organização social. Uma dessas modificações "situa-se no plano das atitudes mentais" levando "o sentimento de que o mundo visível é desprezível, que é preciso fugir dele, que as verdadeiras riquezas estão fora dele" a ser negado "pelo vigor do impulso do progresso, pela chama de uma produção que as violências senhoriais intensificavam" (18).

Ao construir assim seu raciocínio, Duby não estaria, nesse caso, estabelecendo uma empobrecedora relação de causa-efeito entre o econômico e o mental, o infra e o super-estrutural? Não estaria então contrariando sua própria postura de recorrer a termos como féodalisme (e não féodalité) e mode de production seigneurial (e não féodal) "como um chamado e um desafio em face do marxismo tradicional (...) não para ir contra a corrente do marxismo, mas pelo contrário para prolongá-lo, ultrapassá-lo e seguir em direção a outra coisa" (19)? Não estaria nessa preocupação de negar o que o também grande medievalista Jacques Le Goff denominou de 'marxismo vulgar' (20), tangenciando uma posição oposta e igualmente problemática, por exemplo ao considerar que o casamento, colocado "na junção do material e do espiritual (...) sustenta as infraestruturas" (21)?

Muito acima, porém, de um ou outro ponto discutível, a obra de Duby sem dúvida tem o grande mérito de suscitar reflexões e indicar vários caminhos possíveis de pesquisa. Como ficar indiferente ao debate sobre os limites metodológicos entre ideologia e imaginário? Como não desejar trabalhos semelhantes sobre outras regióes da Europa feudal que confirmem ou não o caso do norte francês (22)? Como não pretender a mesma fineza de análise para o material iconográfico (23)? Como não

(18) - Ibidem, p. 257-258.

(19) - O Estido de São Paulo (v. nota 1), p. 9.

(20) - Le Goff, J. As mentalidades. Uma história ambigua, in Le Goff, J. e P. Nora (dir.) História: novos objetos, trad. port. Rio, Francisco Alves, 1976, p. 70

(21) - Le chevalier, p. 23.

(22) - Até este momento tudo indica que o modelo trifuncional era menos forte em regiões nas quais a monarquia - beneficiária última do sistema, pois as três funções peđem uma harmonização regulada por Deus através de seu intermediário, o rei - não tinha condições de manipulá-lo a seu favor: cf. Le Goff, $J$. Les trois functions, $\mathrm{pp}$. 1208-1209.

(23) - $\mathrm{Na}$ verdade isso já foi realizado pelo belo livro do Niccoli, $\mathrm{O}$. I sacerdoti, $i$ guerrieri, $i$ contadini. Storia di un'immagine delle società. Torino, Einaudi, 1979, porém mais para a Idade Moderna que para a Medieval. 
ter $o$ interesse aguçado para $o$ papel que a mulher desempenharia no esquema trifuncional, já que a binaridade sexual perpassa todo o modelo social? Como não pensar nos significados simbólicos do número três enquanto emergência do inconsciente coletivo? Como não se questionar se aquele esquema destinado a manter o campesinato submetido teria realmente atingido aquela massa? Como não supor que tal submissão pode ter se devido mais a instrumentos de coerção física ou de (na verdade não menos violentos) descaracterização do imaginário (stricto sensu) popular? Como enfim não se admirar ao ver revelado diante de nossos olhos que o feudalismo é "antes de tudo um estado de espírito" (24)? Como não se ter despertada a salutar curiosidade por todo um outro lado do feudalismo a ser desvendado?

(24) - Duby, G. La féodalité? Une mentalité médiévale Annales (ESC), 13, 1958, pp. 765-771, reproduzido em Hommes et structures du Moyen Age. Paris, Mouton, 1973, pp. 104 e 110. 